\title{
ARCHEOLOGISCHE KRONIEK
}

\author{
door
}

\section{DESITTERE}

\section{A. OPGRAVINGEN EN VONDSTEN : DE IJZERTIJD}

Voor deze vierde aflevering van de archeologische kroniek houden wij het voorlopig nog bij de oude administratieve indeling van voor de fusie van de gemeenten.

Net als voor de voorgaande periodes beschikken we hoofdzakelijk over toevalsvondsten. Een belangrijke uitzondering hierop wordt nochtans gevormd door de archaeologica uit Destelbergen. Deze zijn ons bekend door de systematische opgravingen door het Seminarie voor Archeologie te Gent. Het ijzertijdmateriaal is vrij eenzijdig en bestaat vooral uit aardewerk. Metalen voorwerpen die met zekerheid aan de ijzertijd kunnen toegeschreven worden werden in het hier behandelde gebied vrijwel niet gesignaleerd. Toch moet men er rekening mee houden dat door hun ongunstige conservatievoorwaarden vele ijzeren voorwerpen kunnen verteerd zijn of door hun gekorrodeerd voorkomen vaak niet als prehistorisch kunnen herkend geweest zijn. Anderzijds moet eraan herinnerd worden dat een aantal types van bronzen voorwerpen nog in omloop waren in de $7 \mathrm{e}$ eeuw, d.w.z. na de aanvang van de ijzertijd. We verwijzen in dit verband naar wat in onze vorige kroniek (Desittere 1975, p. 122) over de Armorikaanse hulsbijlen werd gezegd.

In deze aflevering wordt ook een opsomming gegeven van de Keltische munten die in het Gentse werden gevonden ongeacht of ze dateren uit de tijd voor of na de verovering door Caesar van onze gewesten.

\section{Destelbergen}

Over de begraafplaats uit de late bronstijd en de vroege ijzertijd, gelegen op de plaats Eenbeekeinde, hebben wij het reeds vroeger gehad (Desittere 1974, pp. 143-144). Een aanvullend verslag over 12 graven die tijdens de opgravingscampagnes van 1970 en 1973 te voorschijn kwamen vinde men in O.O.V.O. VII, 1976, pp. 21-30. Tot het urnenveld behoren ook een zestal vierhoekige greppelstrukturen. In de vulling van strukturen nrs. X, XV, XVI en XXXIII werden ijzertijdscherven aangetroffen (o.c. p. 27-30).

\section{Destelbergen}

Behalve het urnenveld (cfr. supra) werden op de plaats Eenbeekeinde nog andere sporen van voorromeinse bewoning aangetroffen. Deze die 
afkomstig zijn van opgravingsvlak A werden systematisch behandeld in O.O.V.O. VII, pp. 30-33. Het gaat in de eerste plaats om eenvoudige strukturen (greppels en kuilen) die weliswaar geen dateerbaar materiaal bevatten maar waarvan de stratigrafische ligging boven het urnenveld en onder de Romeinse lagen, erop kan wijzen dat ze in de ijzertijd of ten laatste in de vroeg-Romeinse periode werden aangelegd. Verder werden in de onderste lagen van opgravingsvlak A 130 ijzertijdscherven gevonden. Belangrijk is dat daaronder voor het eerst ook scherven voorkomen uit de late ijzertijd of $\mathrm{La}$ Tèneperiode.

\section{Drongen}

a. Op de plaats Regenboog.

b. Wandscherf met donkerbruine, gepolijste buitenwand ; klei verschraald met schervengruis. Datering: late bronstijd of vroege ijzertijd.

c. Bewaarplaats : Bijlokemuseum Gent (inv. nr. 10.327).

\section{Drongen}

a. Op de plaats Regenboog, samen met archaeologica uit andere periodes, verzameld door majoor De Poorter in 1924.

b. Lichtbruine besmeten wandscherf verschraald met schervengruis.

c. Bewaarplaats: Museum voor Oudheidkunde van de Rijksuniversiteit Gent (inv. nr. 234). Gift majoor De Poorter.

d. Bibliografie: brief van M. Maertens de Noordhout aan de directeur van het Hoger Instituut voor Kunstgeschiedenis en Oudheidkunde, gedateerd op 27-4-1925 en bewaard in het archief van het Museum voor Oudheidkunde van de Rijksuniversiteit Gent.

\section{Drongen}

a. Op de plaats Regenboog.

b. Fragment van zogenaamde "parasolschaal" uit de late ijzertijd; de buitenwand draagt een plastische versiering, die door uitknijpen met de vingertoppen werd bekomen.

c. Bewaarplaats : verzameling E.P. Jezuieten, Leuven, nr. D569.

d. Bibliografie :

- Mariën 1970, pp. 109-112, 230, fig. 40,10.

- Mariën 1971, pp. 228, 240.

- Leman-Delerive 1973, p. 422, pl. VII, fig. 9.

Opmerking : volgens Mariën ( -1970$)$ is de schaal afkomstig uit een nederzetting ; verdere gegevens hierover ontbreken nochtans, tenzij de vondst deel zou hebben uitgemaakt van de verzameling scherven die in 1919 door Plancquaert (-1924) werden bijeengebracht. Van deze scherven bestaan geen afbeeldingen; over hun datering en plaats van bewaring is ons niets bekend. 


\section{Gent}

a. Samen (?) gevonden in de omgeving van Gent.

b. Twee gouden Keltische munten.

c. Bewaarplaats : in 1808 deel uitmakend van de verzameling van kanunnik M.J. De Bast (Gent).

d. Bibliografie :

- De Bast 1808, p. 32, Pl. I, fig. V. en VI.

\section{Gent}

a. In de omgeving van Gent.

b. Een gouden Keltische munt toegeschreven aan de Nerviërs.

c. Bewaarplaats : in 1813 deel uitmakend van de verzameling van kanunnik M.J. De Bast (Gent).

d. Bibliografie :

- Ghesquière, 1786, p. 35.

- De Bast 1813, p. 191, Pl. III, nr. 14.

- Hermand 1864, p. 169, voetnoot 1.

- Hermand 1865, p. 202.

- De Witte 1888, p. 288.

\section{Gent}

a. Te Gent of omgeving.

b. Een Keltische munt toegeschreven an de Morini.

c. Bewaarplaats : onbekend.

d. Bibliografie :

- Hermand 1865, p. 205.

\section{Gent}

a. Tijdens de havenwerken uitgevoerd in 1914-1918 op het Farmanplein (Port-Arthur).

b. Talrijke scherven uit de ijzertijd; alhoewel ze overwegend behoren tot de late ijzertijd of $\mathrm{La}$ Tèneperiode kunnen enkele randscherven nog tot de Hallstattperiode of vroege ijzertijd opklimmen; de meest voorkomende versiering is deze bekomen door vingertopindrukken; lijn-, kam- en ingestoken versiering komen eveneens voor; onder het dikwandige aardewerk komen zowel scherven met geëffende als met besmeten buitenwand voor; zorgvuldig gegladde waar vindt men daarentegen vooral onder de harder gebakken, dunwandige schaaltjes met geknikte wand ; tot de verzameling behoren eveneens enkele zogenaamde slingerkogels en een drietal spinschijfjes uit aardewerk.

c. Bewaarplaats: Museum voor Oudheidkunde van de Rijksuniversiteit Gent.

Opmerking: in de catalogus van het Gentse universiteitsmuseum worden geen ijzer- 
tijdscherven uit Gent (Port-Arthur) vermeld, wel neolithisch aardewerk (Maertens de Noordhout 1938 b, p. 48, nr. 1800-bis). Vermits er echter geen scherven uit de late steentijd in het universiteitsmuseum aanwezig zijn, die van deze vindplaats zouden afkomstig zijn, mag men veronderstellen dat het materiaal door Maertens de Noordhout foutief werd geïnterpreteerd.

\section{Gent}

a. Tijdens de opgravingen door J. Maertens de Noordhout in 1934 en 1935 ondernomen in de binnentuin van de St.-Baafsabdij.

b. Twintigtal scherven uitgevoerd in prehistorische techniek en die mogelijks tot de voorromeinse ijzertijd kunnen opklimmen. Sommige hebben een besmeten, andere, waaronder een randscherf (fig. 1), hebben een geëffende buitenwand.

c. Bewaarplaats : Bijlokemuseum Gent.

d. Bibliografie :

- Maertens de Noordhout 1935, p. 41.

- Maertens de Noordhout 1938a, pp. 9, 22.

- Mariën 1971, p. 225.

Opmerking : ruim 984 scherven uit de vroege- en de late ijzertijd worden door Maertens de Noordhout vermeld (-1938 a, p. 22). De auteur heeft het bovendien over een "niveau de l'âge du fer" met scherven en dierenbeenderen. Een dergelijke hoeveelheid voorromeins materiaal is in het Bijlokemuseum niet voorhanden. We vermoeden dat de auteur weinig inzicht had in de chronologie van de door hem verzamelde scherven. Bij de beschrijving van zijn ijzertijdmateriaal verwijst hij inderdaad naar foto's van scherven $(-1938$ a, pp. 9-10, fig. 6,2) die duidelijk jonger blijken te zijn. Bovendien zijn de weinige door ons weerhouden en hierboven vermelde scherven weliswaar in prehistorische techniek uitgevoerd maar is het met uitzondering van één enkele randscherf (fig. 1) niet met zekerheid uit te maken dat het wel degelijk om ijzertijdmateriaal gaat en niet eerder om inheems Romeinse waar.

\section{Gent}

a. Materiaal dat rond 1925 en in 1935 door J. Maertens werd verzameld uit een zandige hoogte gelegen op de vroegere gemeente Sint-KruisWinkel.

b. Enkele fragmenten verbrande huttenleem waaronder één met twijgafdruk en 22 scherven uit de late ijzertijd. Deze laatste zijn in verschillende technieken uitgevoerd; sommige hebben een geëffende of besmeten, licht- tot roodbruine buitenwand (fig. 2-6, 9-10), andere (fig. 7-8) zijn harder gebakken en hebben een licht- tot donkerbruine, geëffende tot glad gepolijste buitenwand. Enkele scherven zijn versierd met vingertopindrukken bovenop de rand (fig. 2,9), andere dragen lijnversiering op de buitenwand (fig. 8).

c. Bewaarplaats : Bijlokemuseum Gent (inv. nr. 9952).

d. Bibliografie :

- Maertens 1927, pp. 51, 55.

- Maertens de Noordhout 1935, p. 36. 
Opmerking: over de verkeerde toewijzing van deze vondsten tot de bronstijd zie Desittere 1975, p. 117, nr. 30.

\section{Gentbrugge}

a. In 1867 of 1868 gevonden tijdens werken uitgevoerd voor de aanleg van de ringspoorweg aan de Neder-Schelde, vermoedelijk ter hoogte van de Heernisbrug.

b. Aardewerkbekertje daterend uit de aanvangsfaze van de late ijzertijd ; de beker heeft een standring, een bikonisch lichaam, cylindervormige hals en wijd uitstaande bovenrand; buik, hals en bovenrand zijn van elkaar gescheiden door een horizontale groeflijn, het halsveld is bovendien versierd met lijnen die een geometrisch motief vormen; donkerbruine tot zwarte, goed gepolijste buitenwand.

c. Bewaarplaats : Kon. Musea voor Kunst en Geschiedenis, Brussel (inv. nr. B 479).

d. Bibliografie :

- De Loë 1931, p. 172, fig. 79.

- Mariën 1945, p. 19.

\section{Oostakker}

a. Vermoedelijk gevonden op de plaats Meuleke.

b. Acht scherven uit de late ijzertijd vervaardigd in verschillende technieken; twee zijn dikwandig met besmeten buitenwand, één randscherf draagt vingertopindrukken bovenop de rand (fig. 11) en heeft een geëffende, lichtbruine buitenwand ; 4 harder gebakken scherven hebben een lichtbruine, gepolijste buitenwand; 1 daarvan is versierd met cirkelvormige, ingestempelde depressies (fig. 12).

c. Bewaarplaats : Bijlokemuseum Gent (inv. nr. 10319-10326). Gift J. Maertens de Noordhout.

Opmerking: er is ons geen litteratuur over deze vindplaats bekend. De scherven bevinden zich, samen met postromeinse keramiek, in het Bijlokemuseum onder de aanduiding: Oostakker-Meulestede. Daar de wijk Meulestede volledig op het grondgebied Gent gelegen is en op behoorlijke afstand van de westgrens van de gemeente Oostakker vermoeden we dat het hier gaat om de plaats Meuleke.

\section{Sint-Denijs-Westrem}

a. In juni 1907 gevonden op het voormalige Oefenplein, thans vliegveld (kad. Sie A, 259 p.).

b. Dertigtal scherven van ruwwandig tot fijn geglad aardewerk uit de late ijzertijd; daaronder twee randfragmenten (fig. 13, 15) met donkerbruine, geëffende buitenwand, een donkerbruin wandfragment met pseudo-kamversiering (fig. 16) en een dikwandig (14 mm) lichtbruin wandfragment met onregelmatig geplaatste vingertopindrukken (fig. 14). 
c. Bewaarplaats : Bijlokemuseum Gent (inv. nr. 9973). Gift van J. Maertens de Noordhout.

Een aantal sites worden in de litteratuur vermeld die vondsten uit de ijzertijd zouden opgeleverd hebben. Er zijn ons noch over de aard noch over de bewaarplaats van de voorwerpen nadere gegevens bekend. Het gaat om volgende vindplaatsen :

Afsnee : uit de bibliografische gegevens vermeld in het repertorium van Oost-Vlaanderen (Bauwens-Lesenne 1962, pp. 7-8) kan niet besloten worden dat er in 1910 te Afsnee ijzertijdmateriaal zou gevonden zijn. Wel werden er toen, naast archaeologica uit de late steentijd (Desittere 1973, p. 250) en de bronstijd (Desittere 1974, pp. 141-142), ook aardewerkscherven gevonden. Daar zij niet meer bewaard zijn en bovendien nergens op afdoende wijze beschreven of afgebeeld zijn, tasten wij over hun datering in het duister.

Merelbeke : diverse voorwerpen uit de ijzertijd vermeld bij Vander Maelen 1863 en Bauwens-Lesenne 1962, p. 125.

Wondelgem : site met „La Tène III” materiaal vermeld bij Mariën 1971, p. 240.

Leopoldkanaal: aardewerk uit de eerste ijzertijd zou in 1848 gevonden zijn tijdens de graafwerken voor het Leopoldkanaal, in de 19e eeuw ook bekend onder de benaming "kanaal van Zelzate" (Schayes 1854, p. 102, nr. 293 ; De Loë 1891, p. 156 ; Comhaire 1894, p. 166).

\section{B. VARIA EN PERSONALIA}

- Op zaterdag 13 juni 1976 werd door de Maatschappij voor Geschiedenis en Oudheidkunde te Gent een archeologische dag ingericht. Professor Dr. S.J. De Laet sprak ter dier gelegenheid over de opgravingen te Destelbergen. Meer in het bijzonder belichtte de spreker het belang van de Gallo-Romeinse vicus voor de vroegste geschiedenis van Gent. De dag werd afgesloten met een bezoek aan de opgravingen.

-- Van 11 december 1976 tot 31 januari 1977 greep in de gewezen St.Pietersabdij te Gent een archeologische tentoonstelling plaats onder het motto "Graven naar Gents Verleden". De tentoonstelling werd georganiseerd door de Dienst Archeologie en Historische Monumenten, het Centrum voor Kunst en Cultuur en de Oudheidkundige Musea van de stad Gent, het Seminarie voor Archeologie van de Rijksuniversiteit Gent, diverse archeologen en heemkundige kringen uit Gent en omgeving. 


\section{LIJST DER AFBEELDINGEN}

Aardewerk

1. Gent, St.-Baafsabdij.

2-10. Gent, St.-Kruis-Winkel.

11-12. Oostakker.

13-16. St.-Denijs-Westrem.

\section{BIBLIOGRAFISCHE AFKORTINGEN}

Bauwens-Lesenne 1962 = M. Bauwens-Lesenne, Bibliografisch repertorium der oudbeidkundige vondsten in Oost-Vlaanderen, Oudheidkundige Repertoria II, Brussel, 1962.

Comhaire 1894 = Ch.-J. Comhaire, Les premiers âges de métal dans les bassins de la Meuse et de l'Escaut, Bulletin de la Société d'Anthropologie de Bruxelles 13, 1894, pp. 97-226.

De Bast 1808 = M.J. De Bast, Recueil d'antiquités romaines et gauloises trouvées dans la Flandre proprement dite, Gent, 1808.

De Bast 1813 = M.J. De Bast, Recueil d'antiquités romaines et gauloises, second supplément, 1813.

de Loë 1891 = A. de Loë, Quelles sont les découvertes relatives à l'âge du bronze et au premier âge du fer qui ont été faites jusqu'ici en Belgique et quelles sont les conséquences à en tirer? Annales de la Fédération Archéologique et Historique de Belgique, 7e congrès, Brussel, 1891, I, pp. 131-157.

de Loë 1931 = A. de Loë, Belgique Ancienne. Catalogue descriptif et raisonné. II. Les âges du métal. Brussel, 1931.

Desittere 1973 = M. Desittere, Archeologische Kroniek, Handelingen der Maatschappij voor Geschiedenis en Oudheidkunde te Gent 27, 1973, pp. 249-252.

Desittere $1974=$ M. Desittere, Archeologische Kroniek, Handelingen der Maatschappij voor Geschiedenis en Oudheidkunde te Gent 28, 1974, pp. 141-158.

Desittere $1975=$ M. Desittere, Archeologische Kroniek, Handelingen der Maatschappij voor Geschiedenis en Oudheidkunde te Gent 29, 1975, pp. 117-127.

De Witte 1888 = A. De Witte, Etat actuel de la numismatique nervienne, Annales de la Fédération Archéologique et Historique de Belgique IV, 2, 1888, pp. $275-293$.

Ghesquière $1786=\mathrm{J}$. Ghesquière, Mémoire sur trois points intéressans de l'bistoire monétaire des Pays-Bas, Brussel, 1786.

Hermand 1864 en $1865=$ A. Hermand, Numismatique Gallo-belge de l'bistoire monétaire des Atrébates, des Morins et des nations gallo-belges en général, Revue de la numismatique belge, 4e r, II, 1864, pp. 149-201; III, 1865, pp. 177-209.

Leman-Delerive 1973 = G. Leman-Delerive, La coupe à bords ourlés, chronologie, utilisation et répartition à l'époque de La Tène, L'Antiquité Classique 42, 1973, pp. 406-426.

Maertens 1927 = J. Maertens, Identification de parties de la voie romaine d'Anvers vers la mer du nord, Bulletijn der Maatschappij van Geschied- en Oudheidkunde te Gent 35, 1927, pp. 45-57.

Maertens de Noordhout $1935=$ J. Maertens de Noordhout, Nouvelles fouilles dans la Flandre Orientale, Bulletijn der Maatschappij van Geschied- en Oudheidkunde te Gent 42-43, 1934-1935, pp. 36-42.

Maertens de Noordhout $1938 \mathrm{a}=\mathrm{J}$. Maertens de Noordhout, Fouilles exécutées à l'Abbaye de Saint-Bavon à Gand, Bulletijn der Maatschappij van Geschieden Oudheidkunde te Gent 46, 1938, pp. 5-24. 
Maertens de Noordhout $1938 \mathrm{~b}=\mathrm{J}$. Maertens de Noordhout, Catalogue du musée des antiquités de l'université de Gand, St.-Amandsberg 1938.

Mariën 1945 = M.E. Mariën, Note sur une bouterolle de l'âge du bronze, découverte à Gentbrugge, Bulletin des Musées royaux d'Art et d'Histoire, 3e reeks, 17, 1945, pp. 19-21.

Mariën 1970 = M.E. Mariën, Le Trou de l'Ambre au Bois de Wérimont Eprave, Monographies d'Archéologie Nationale 4, Brussel 1970.

Mariën $1971=$ M.E. Mariën, Tribes and Archaeological groupings of the La Tène period in Belgium: some observations. The European Community in Later Prehistory, Studies in Honour of C.F.C. Hawkes, London, 1971, pp. 211-241.

O.O.V.O. VII $=$ Oudheidkundige Opgravingen en Vondsten in Oost-Vlaanderen VII, Kultureel Jaarboek voor de provincie Oost-Vlaanderen, Bijdragen, Nieuwe reeks 2, 1976.

Plancquaert $1924=$ R.P. Plancquaert, $A$ propos de quelques découvertes faites dans la Flandre Orientale, Bull. Soc. d'Anthrop. de Bruxelles 39, 1924, pp. 191. 194.

Schayes 1854 = A.G.B. Schayes, Catalogue du Musée royal d'Armures, d'Antiquités et d'Ethnologie, Brussel, 1854.

Vander Maelen 1863 = J. Vander Maelen, Carte archéologique, ecclésiastique et nobiliaire de la Belgique, Brussel, 1863. 

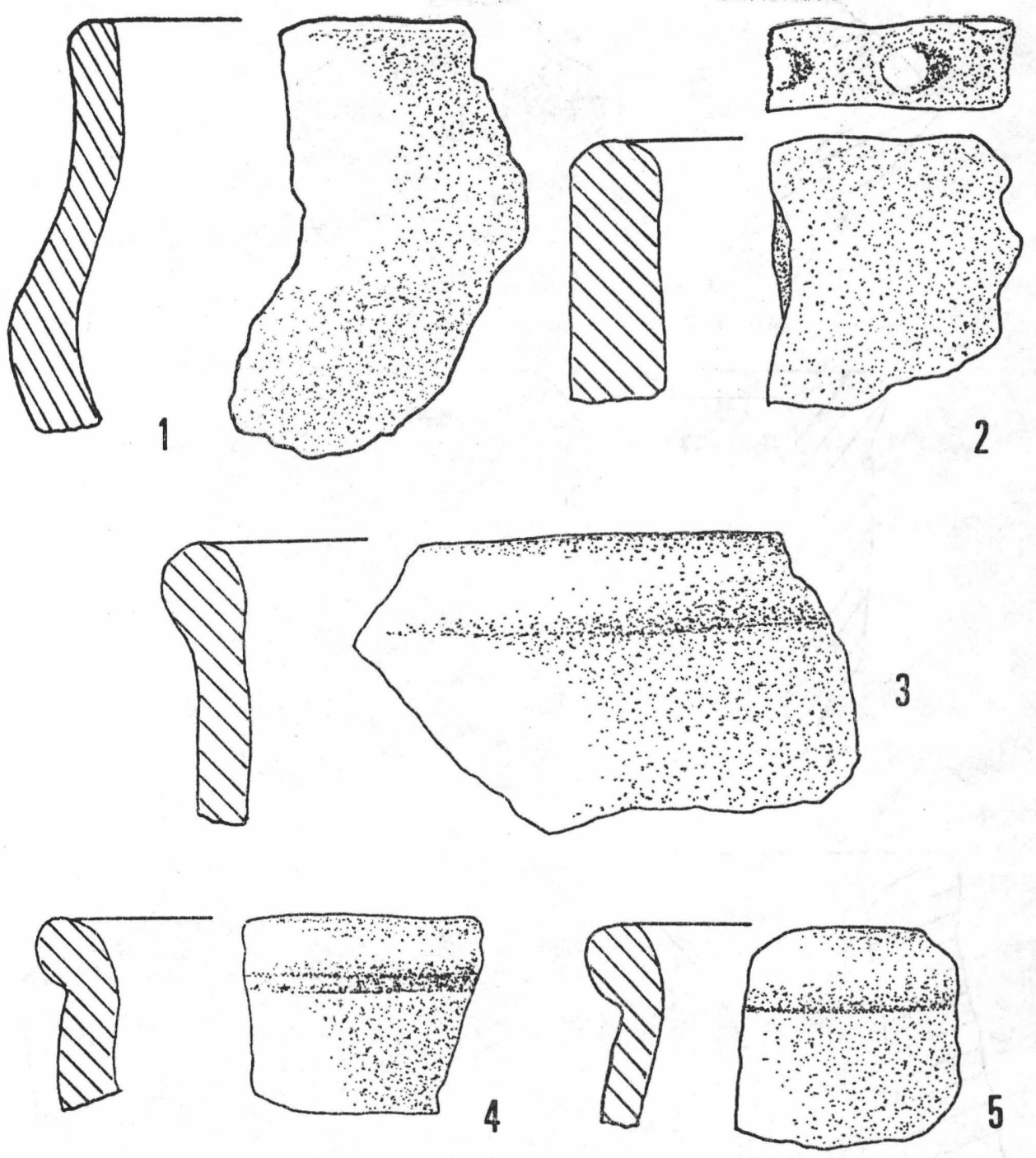

5
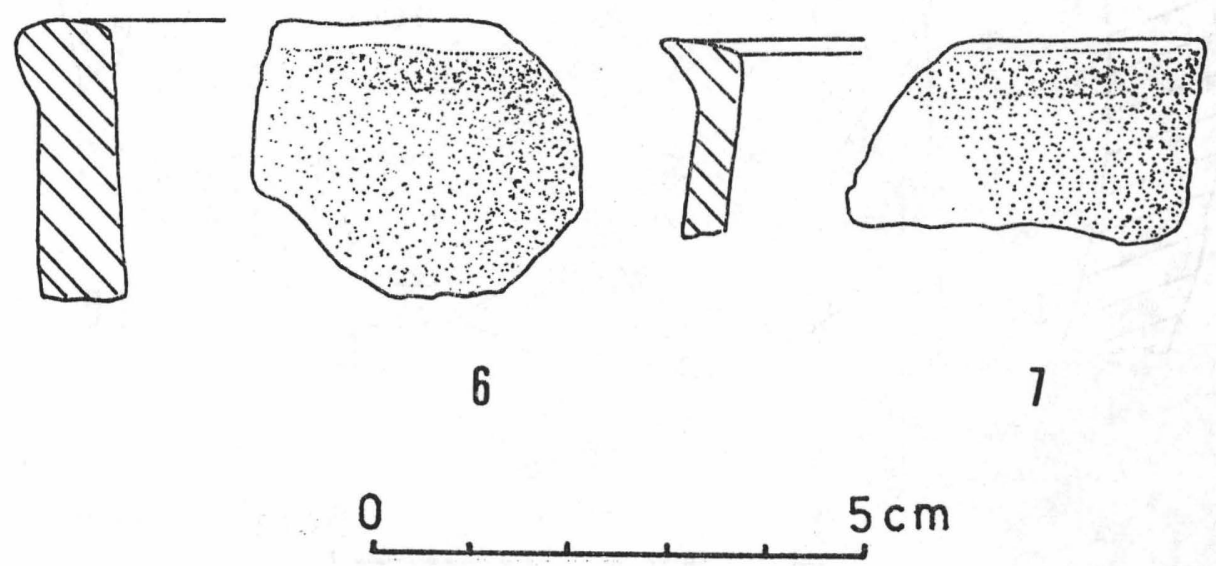

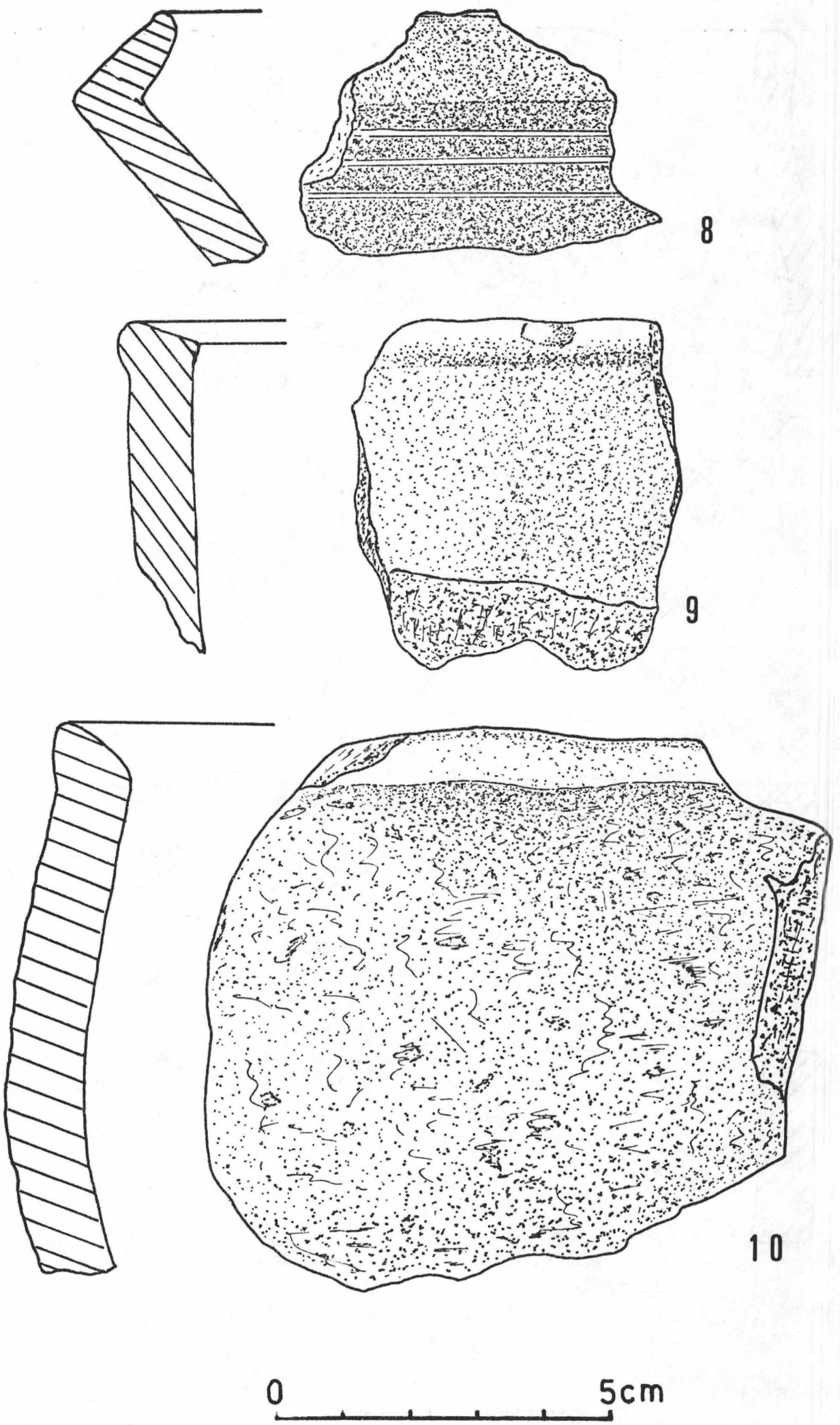


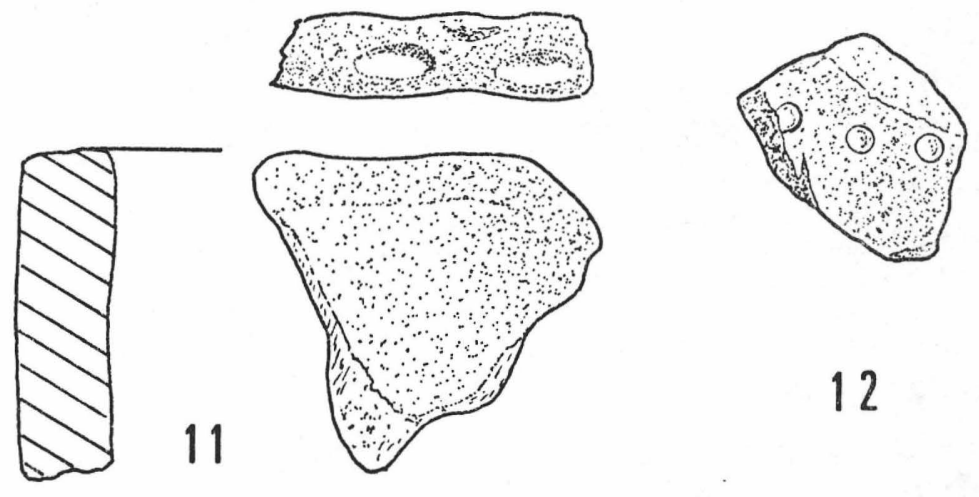

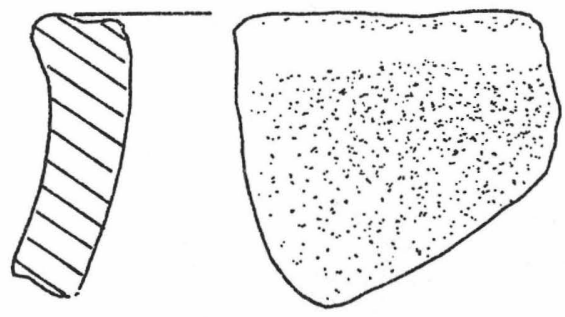

13

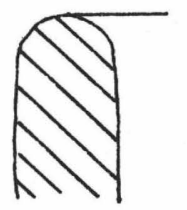

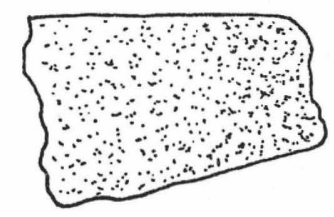

15

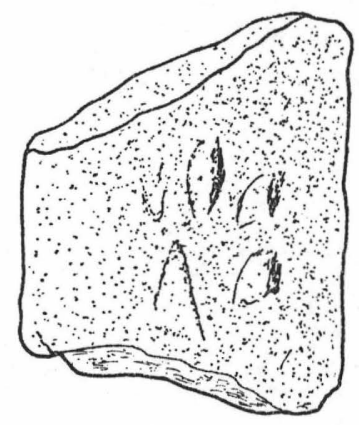

14

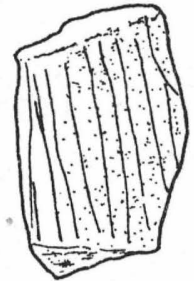

16

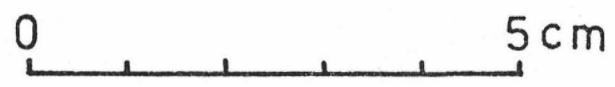

